\title{
Allochthonous inputs: integrating population changes and food-web dynamics
}

Robert L. Jefferies

Most ecosystems are recipients of allochthonous materials that enhance in situ productivity. Recent theoretical and empirical studies suggest that low to moderate inputs can stabilize food webs. However, depending on the trophic levels that use the resource, food webs can become unstable as inputs increase. Where large amounts of agricultural resources are transferred to natural habitats, trophic dynamics change: trophic cascades can occur and rare or uncommon species can become invasive. Rates of change in species abundances can also be amplified by the effects of changes in legislation and management practices on subsidized consumers.

Robert L. Jefferies is at the Dept of Botany, University of Toronto, 25 Willcocks Street, Toronto, Ontario, Canada M5S 3B2 (jefferie@botany.utoronto.ca).

Ecosystems are both donors and recipients of allochthonous nutrients [e.g. nitrogen (N), carbon (C) and phosphorus (P)] and detritus, without which net primary productivity and foodweb dynamics in systems of low in situ productivity cannot be sustained1. The movement of these subsidies (allochthonous materials) is strongly scale-dependent. Some subsidies are transported at the intercontinental scale, whereas the movement of others is restricted to a scale of a few metres or less. Both physical and biotic vectors transfer the subsidies, which can be the direct result of feedback processes between the donor system and the recipient ('recipient controlled') or the transfer processes can be independent of the recipient ('donor controlled')2.

Recent papers1,3-9 have drawn attention to these spatial subsidies, which dramatically affect food-web dynamics and the availability of resources for consumers. The subsidies enable consumer populations to achieve numbers greater than those supported by in situ productivity. In extreme cases, consumer populations increase to such high levels that prey populations of primary or secondary producers are depleted, leading to a trophic cascade1,4,6,8.

The prime purpose of this article is to draw attention to the direct and the indirect consequences of the large-scale transfer of resources from agricultural sources to natural communities. In particular, I will focus on the role of colonial birds as both vectors and recipients of agricultural subsidies. The resultant changes in food-web dynamics have dramatically affected the population numbers of certain bird species that have been accompanied by unforseen changes in community and ecosystem function changes that are still taking place. 


\section{Predictions of the effects of allochthonous inputs on food-web stability}

Empirical and theoretical papers1,3-9 stress that the conceptual framework of food-web dynamics should not only include the transfer of autochthonous materials along food chains, but also should include allochthonous inputs and information on which trophic levels are recipients of subsidies. Early modeling studies 2,10 indicated that donor-controlled nutrient additions can affect primary productivity and can lead to bottom-up control of trophic dynamics that might result in longer food chains, higher growth rates of populations and higher carrying capacities2,10. However, high inputs can destabilize systems bringing about extinction of top species in a food chain as a result of 'the paradox of enrichment'11.

Inputs can also affect other trophic levels, and a major contribution of recent papers has been the examination of the direct effects of allochthonous inputs at the consumer level, which previously had not been well studied1,6,12. The effects of inputs on stability in well established food-chain models13,14 indicate that low levels of allochthonous inputs stabilize food-web dynamics when consumer species preferentially feed on autochthonous sources. By contrast, if inputs are increased or feeding preferences of consumers are changed in favor of external sources, the food chain becomes decoupled with a loss of species7,8. Hence, similar to the earlier findings at the basal trophic level, theoretical predictions indicate that parallel food chains (multichannel resources) that are based on donor-controlled allochthonous food sources affect local consumer-resource interactions and can dampen or facilitate trophic cascades depending on the magnitude and type of the inputs6,8. Although empirical studies provide support for the instability of systems when inputs are high (see later), evidence of stability at low to moderate inputs is less forthcoming 3,4 and additional field studies are needed to test the predictions.

\section{Regulation of transfer of allochthonous material}

Although there are not many quantitative studies regarding the contribution that allochthonous materials make to the energy or the nutrient budgets of ecosystems, an important determinant of the transfer rate is the perimeter:area $(\mathrm{P}: \mathrm{A})$ ratio of the ecosystem, particularly where physical vectors transfer the subsidy1. This is a measure of the 'permeability' of the system to both the influx and efflux of materials. An increase in this ratio is expected to lead to increased permeability. For example, in river systems the P:A ratio declines from head-water streams to large rivers, which results in a downstream decline in the importance of local terrestrial allochthonous inputs in driving productivity15. Large rivers are sinks for material derived upstream. Coastal terrestrial ecosystems, which also have a large P:A ratio, are a further dramatic example: allochthonous material derived from marine sources provides a nutrient and energy subsidy to terrestrial communities, particularly where in situ productivity of coastal habitats (e.g. coastal deserts) is low compared with that of adjacent marine systems3,4,16. Upwelling of nutrients in marine systems drives oceanic production. It occurs below $0.1 \%$ of surface of the oceans, where $50 \%$ of the world's fish are caught17,18. Nesting sea birds and mammals that feed on fish move large quantities of organic material to coastal terrestrial sites and oceanic islands, resulting in 
significantly greater plant and arthropod abundances around seabird colonies. Worldwide, seabirds transfer an estimated 104-105 tons of phosphorus to terrestrial environments1,19.

Many of these interactions between consumers and allochthonous materials are donor-controlled. For example, an estimated 13 million tons of Saharan dust are deposited in the Amazon basin annually20. Nutrients (potassium, ammonium, nitrate and phosphate ions) in the dust are believed to be critical for the functioning of tropical rainforests 21 . In the case of recipient-control, transfer to the consumer is usually controlled by feedback mechanisms between the recipient and the source of the allochthonous material. In the Netherlands, grazing of grassland sites by large flocks of Brent geese (Branta bernicia) every 3 to 5 days is a consequence of vegetation regrowth following defoliation, which is sustained long term largely by faecal enrichment (derived from food obtained from allochthonous sources)22. The geese act as both a nutrient vector and a consumer.

\section{Agricultural subsidies and bird populations}

An important and unresolved question is the extent to which allochthonous materials, derived from agriculture, are moving into natural habitats and changing community structure and trophic dynamics, possibly leading to trophic cascades23-25. The cascade can occur either where just two trophic levels (herbivores and primary producers) are represented (but where herbivores are manipulated directly or indirectly by anthropogenic agencies) or where three or four trophic levels are present. In either case, it brings about a severe reduction in the numbers of organisms and/or the biomass at the trophic level below that of the consumer.

Wildlife appears to be an important conduit for the transfer of nutrients from agricultural lands to natural habitats, particularly where high densities of animals occur. Migratory waterfowl are often present as dense aggregations, reflecting increased numbers of birds and a reduction in the area of suitable wetlands. In New Mexico, daily feeding bouts by geese move large quantities of nutrients from farm fields where they feed, to managed wetlands where they roost9. Loading rates peak at $300 \mathrm{~kg} \mathrm{~N}$ day 21 and $30 \mathrm{~kg} \mathrm{P}$ day21 in 50 ha of wetland. Bird-borne nutrients supply $40 \%$ of the $\mathrm{N}$ and $75 \%$ of the $\mathrm{P}$ entering the wetland. Wetlands are generally considered to be $\mathrm{N}$-limited or N-P co-limited, and much of the $\mathrm{N}$ and $\mathrm{P}$ in bird faeces is highly soluble and readily absorbed by aquatic algae, bacteria and macrophytes. At present, bird-borne nutrients influence water quality in the roosting areas only, but ever-increasing goose densities might lead to long-term changes in water quality and species assemblages in the entire refuge 26.

Of particular interest are cases in which rare or uncommon species have become invasive as a result of an increase in allochthonous inputs either to the primary producers or to the consumers. Often the changes have been accentuated by changes in management practices and in legislation regarding the status of these species. 


\section{Effects of agriculture on migratory cormorants}

The first case study is the increase in migratory cormorant (Phalacrocorax carbo) numbers in managed wetlands in continental Europe27,28. In the 1950s, the population of European cormorants had become small and localized; most were bred in the Netherlands. Subsequently, the species has profited both from legal protection and from an overall increase in fish populations owing to eutrophication of meres (shallow lakes) as a result of inputs from agricultural sources. Inputs of $\mathrm{N}$ and $\mathrm{P}$ into shallow lakes promoted algal growth, which affected trophic dynamics and led to an increase in non-Salmonidae fish populations when overfishing had removed the predatory fish. The changes in fish populations were not uniform and were dependent on local conditions28. The general trend was towards large fluctuations in the size of fish populations with a dominance of small, early maturing, short-lived non-Salmonidae fish, such as perch (Perca fluviatilis), ruffe (Gymnocephalus cernuus), smelt (Osmerus eperlanus), roach (Rutilus rutilus) and bream (Abramus brama), on which the cormorants fed. Recovery of the cormorant population started in the Netherlands in the late 1960s and the 1970s, and the increase in local population sizes ranged from $10 \%$ to $25 \%$ per annum 27 . Cormorants are opportunistic feeders and have resorted to mass-flock fishing on shoaling young fish, where there is a high stock of pelagic fish. They have brought about a drastic reduction of planktivorous fish in some lakes, which has resulted in clear water. Before predation, the fish efficiently depressed zooplankton, which, in turn, were unable to graze down algal populations27. Removal of fish led to a marked increase in zooplankton, heavy grazing of algae and the presence of clear water in some eutrophic lakes27. Although a dramatic recovery of the cormorant population has occurred in response to protection, eutrophication and changes in foraging habits, the populations are unstable: the recent collapse of cormorant populations on the ljsselmeer (lake) (The Netherlands) from unknown causes emphasizes the instability in their population growth. Similar marked shifts in numbers have occurred in some populations of the American double-crested cormorant (Phalacrocorax auritus)29.

\section{Effects of agriculture on geese}

A well documented example of the causes and the effects of agriculture on trophic relationships is the high number of 'white' geese in North America (lesser snow geese, Anser caerulescens caerulescens; greater snow geese, A.c. atlantica; and Ross' geese, A. rossii30,31). A major influence on population growth has been the conversion of natural habitats to cropland and grassland. This has led to expanded migration routes and winter ranges, because the geese exploit an energy-nutrient subsidy (agricultural crops: grain and young plants) for up to eight months of each year. In addition, as a result of changes in legislation, refugia have been established along the flyways and on the wintering grounds, which provide protection and often food supplements. In particular, the mid-continent population of lesser snow geese has shown a dramatic exponential rise in numbers in recent decades to .5 million birds. Traditionally, the population migrated along the Mississippi and Missouri rivers and wintered in the coastal salt marshes of the Gulf States. However, with the development of intensive agriculture since the 1950s and the establishment of flyway refugia, many birds fail to winter in the coastal salt marshes and instead feed extensively in maize, wheat, rice and soybean fields, often on spent grain or seed. 
This phenomenon has led to an expansion of the geographical range and a change in the birds migration routes. The rise in geese population numbers since the $1950 \mathrm{~s}$ is broadly coincident with the development of intensive agriculture in North America, and the increased use of fertilizers, particularly $\mathrm{N}$-based fertilizers32. It is significant that by 1990 the Midwestern states and Texas accounted for $\sim 40 \%$ of all the $\mathrm{N}$ fertilizer used in the USA (Ref. 32). The migration routes of the mid-continent population of lesser snow geese pass through these states. This energy-nutrient subsidy, as well as additional factors, have limited the occurrence of classic density-dependent regulation of the mid-continent population.

The negative effects of the subsidy on trophic dynamics are expressed on the staging, nesting and brood-rearing habitats in the eastern Canadian Arctic, particularly the coastal areas of the Hudson Bay. Here, coastal vegetation has been partially destroyed by the foraging activities of large numbers of geese. In particular, coastal intertidal marshes have been degraded by both biotic and physical processes that have led to hypersalinity, soil erosion and little or no reestablishment of vegetation33. As a result of the cumulative effects of geese foraging activities, about a third of the coastal salt marshes have been converted to mudflats along the shores of Ontario and Manitoba, with little likelihood of vegetation re-establishing in the immediate future. There are additional changes to local community assemblages and to trophic dynamics associated with the effects of the trophic cascade. The loss of vegetation has been accompanied by a decline in the densities of breeding populations of some shore bird species as well as a loss of soil invertebrate assemblages such as spiders and beetles. The biological impoverishment of coastal intertidal communities at the local and regional scale has been triggered mainly by a nutrient subsidy that is donor-controlled $3000-5000 \mathrm{~km}$ away from these Arctic sites. Thus, the consequences of the energy-nutrient subsidies are manifest both in the Arctic and in the southern wintering grounds.

The comparable increase in the population size of giant Canada geese (Branta canadensis maxima) is also thought to be linked to nutrient subsidies from agricultural and urban sources30. In the 1950s, the population of this subspecies was limited to $\sim 50000$ birds that bred in central Manitoba. Today, the population is estimated to be .5 million birds, and large numbers of moult migrants from southern Canada and the USA frequent the coasts of Hudson and James Bays in summer, contributing to the loss of vegetation as a result of their foraging activities34.

\section{Effects of agriculture on eared dove}

A characteristic of the studies described here is the rapid increase in the population numbers of birds that occupy different positions in food webs in response to changes in agricultural practices. A particularly striking example of this is the change in numbers of eared doves (Zenaida auriculata) in Argentina35. This species, which was abundant on the Pampas in the past century, declined markedly between 1870 and 1890 when the grasslands were ploughed, probably as a result of the scarcity of thistle and grass seeds. However, when sorghum (Sorghum bicolor) was grown this century, birds fed on the crop and their numbers increased dramatically, but only where dense secondary scrub provided nest 
sites and where a water source was available. In recent decades, soybean (Glycine max), which is a more attractive crop for farmers, has replaced sorghum and once again dove numbers have declined35.

\section{Conclusions}

These examples of changes in trophic dynamics, associated with large inputs of allochthonous materials, are widespread and ongoing; the effects are cumulative and they are governed by feedback processes that involve both biotic and abiotic processes. The donor system is often present on a large spatial scale, whereas when intensive effects of trophic cascades occur they are manifest at the local scale (,15 km). The animals effectively act as a concentrating mechanism in bringing about these effects at the local scale. However, because of the increased coalescence of damaged fragmented areas, the changes can be represented at the regional scale, as in the case of the effects of the geese on coastal intertidal marshes (,2000 km, where changes are manifest at both the community and ecosystem levels).

Although the identification of nutrient and detrital subsidies is relatively straightforward, the subsequent changes to trophic dynamics are less easy to predict. In particular, the anthropogenic influences extend beyond the direct subsidy to include changes in legislation and in management practices of agricultural lands and wildlife refuges, which act to amplify the direct effects of the subsidy. Hence, there is a need for further field studies of changes in trophic dynamics where allochthonous inputs are high.

Several theoretical issues also provide a focus for future studies. Most attempts at modeling food webs are based on linear food chains, which are interconnected in the natural world6-8, but the influence of the interconnections on food web stability is largely unknown8,36. Allochthonous inputs can result in parallel food chains that might bring about an increase in the number of connections between chains leading to the establishment of a web3,4. Thus, the amount and type of resource input and the degree of preferential feeding by consumers on allochthonous inputs can influence stability 36 . At first glance, this conclusion contrasts with earlier predictions of decreased stability when omnivory increases at different trophic levels in the absence of external inputs37. However, this might have been the outcome of the use of strong consumer feeding preferences for food sources in earlier models8. Strong links of this type tend to destabilize systems in all models, as indicated above8. Thus, models need to include a variable feeding preference term rather than a fixed term, which is more characteristic of real food webs36. The term could represent changes in the use of allochthonous and autochthonous materials along a resource gradient, or the impact of spatial and temporal heterogeneity in resource availability8,38.

\section{Acknowledgements}

I thank Ken Abraham, Mennobart van Eerden, Peter Kotanen, John Maron, Gary Polis, David Post, Gary Sprules and Chip Wesloh for helpful discussions and for preprints of papers. I am also grateful to NSERC, Canada for financial support for this study. Mrs Catherine Siu kindly typed the manuscript. 


\section{References}

1 Polis, G.A. et al. (1997) Towards an integration of landscape and food web ecology: The dynamics of spatially subsidized food webs. Annu. Rev. Ecol. Syst. 28, 289-316

2 DeAngelis, D.L. (1980) Energy flow, nutrient cycling, and ecosystem resilience. Ecology 61, 764-771

3 Polis, G.A. and Hurd, S.D. (1995) Extraordinarily high spider densities on islands: Flow of energy from the marine to terrestrial food webs and the absence of predation. Proc. Natl Acad. Sci. U.S.A. 92, 4382-4386

4 Polis, G.A. and Hurd, S.D. (1996) Allochthonous input across habitats, subsidized consumers, and apparent trophic cascades: examples from the ocean-land interface. In Food Webs, Integration of Patterns and Dynamics (Polis, G.A. and Winemiller, K.O., eds), pp. 275-285, Chapman \& Hall

5 Power, M.E. (1990) Effect of fish in river food webs. Science 250, 411-415

6 Polis, G.A. and Strong, D. (1996) Food web complexity and community dynamics. Am. Nat. 147, 813-846

7 McCann, K. and Hastings, A. (1997) Re-evaluating the omnivory-stability relationships in food webs. Proc. R. Soc. London Ser. B 264, 1249-1254

8 Huxel, G.R. and McCann, K. (1998) Food web stability: the influence of trophic flows across habitats. Am. Nat. 152, 460-469

9 Post, D.M. et al. (1998) The role of migratory waterfowl as nutrient vectors in a managed wetland. Conserv. Biol. 12, 910-920

10 DeAngelis, D.L. (1992) Dynamics and Nutrient Cycling, and Food Webs, Chapman \& Hall

11 Rosenzweig, M.L. (1971) Paradox of enrichment: destabilization of exploitation ecosystems in ecological time. Science 171, 385-387

12 Polis, G.A. et al. (1996) Time, space, and life history: influences on food webs. In Food Webs, Integration of Patterns and Dynamics (Polis, G.A. and Winemiller, K.O., eds), pp. 435-460, Chapman \& Hall

13 Yodzis, P. and Innes, S. (1992) Body size and consumer resource dynamics. Am. Nat. 139, 1151-1175

14 McCann, K. and Yodzis, P. (1995) Bifurcation structure of a threespecies food chain model. Theor. Popul. Biol. 48, 93-125

15 Vannote, R.L. et al. (1980) The river continuum concept. Can. J. Fish. Aquat. Sci. 37, 130-137

16 Odum, E.P. (1970) Fundamentals of Ecology (3rd edn), Saunders

17 Barnes, R.S.K. and Hughes, R.N. (1988) An Introduction to Marine Ecology, Blackwell

18 Barry, J.P. and Dayton, P.K. (1991) Physical heterogeneity and the organization of marine communities. In Ecological Heterogeneity (Kolasa, J. and Pickett, S.T., eds), pp. 270-320, Springer-Verlag

19 Murphy, G.I. (1981) Guano and the anchovetta fishery. Res. Manag. Environ. Uncert. 11, 81-106

20 Swap, R. et al. (1992) Saharan dust in the Amazon basin. Tellus B 44, 133-149

21 Vitousek, P.M. and Sanford, R.L., Jr (1986) Nutrient cycling in moist tropical forest. Annu. Rev. Ecol. Syst. 17, 137-167

22 Drent, R.H. and Prins, H.H.T. (1987) The herbivore as a prisoner of its food supply. In Disturbance in Grasslands (van Andel, J. et al., eds), pp. 131-148, Kluwer

23 Strong, D. (1992) Are trophic cascades all wet? Differentiation and donor control in species ecosystems. Ecology 73, 747-754

24 Lawton, J.H. (1989) Food webs. In Ecological Concepts (Cherrett, J.M., ed.), pp. 43-78, Blackwell

25 Vitousek, P.M. (1994) Beyond global warming: ecology and global change. Ecology 75, 1861-1876

26 Kitchell, J.F. et al. (1999) Nutrient cycling at the landscape scale: the role of diel foraging migrations by geese at the Bosque del Apache National Wildlife Refuge, New Mexico. Limnol. Oceanogr. 44, 828-836
27 van Eerden, M.R. et al. (1995) Riding on the crest of the wave: possibilities and limitations for a thriving population of migratory cormorants Phalacrocorax carbo in man-dominated wetlands. Ardea 83, 1-9

28 De Nie, H. (1995) Changes in the inland fish populations in Europe in relation to the increase of the cormorant Phalacrocorax carbo sinensis. Ardea 83, 115-122

29 Weseloh, D.V. et al. (1995) Double-crested cormorants of the Great Lakes: changes in population size, breeding distribution and reproductive output between 1913 and 1991. Colon. Waterbirds 18 (Spec. Publ. 1), 48-59

30 Abraham, K.F. et al. (1996) Why are there so many white geese in North America? In 7th International Waterfowl Symposium (Ratti, J.T., ed.), pp. 79-92, Ducks Unlimited

31 Ankney, C.D. (1996) An embarrassment of riches: too many geese. J. Wildl. Manage. 60, 217-223

32 Lanyon, L.E. (1995) Does nitrogen cycle? Changes in the spatial dynamics of nitrogen with industrial nitrogen fixation. J. Prod. Agric. 8, 70-78

33 Jefferies, R.L. (1999) Herbivores, nutrients and trophic cascades in terrestrial environments. In Herbivores: Between Plants and Predators (OIff, H. et al., eds), pp. 301-330, Blackwell

34 Abraham, K.F. and Jefferies, R.L. (1997) High goose populations: causes, impacts and implications. In Arctic Ecosystems in Peril (Batt, B.D., ed.), pp. 7-72, US Fish and Wildlife Service and Canadian Wildlife Service

35 Bucher, E.H. (1990) The influences of changes in regional land-use patterns on Zenaida dove populations. In Granivorous Birds in the Agricultural Landscape (Pinowski, J. and Summer-Smith, J.D., eds), pp. 291-303, Proceedings of General Meetings of the Working Group on Granivorous Birds, INTERCOL

36 Post, D.M. et al. Prey preference by a top predator and the stability of linked food chains. Ecology (in press)

37 Pimm, S.L. and Lawton, J.H. (1978) On feeding on more than one trophic level. Nature 275, 542-544

38 Oksanen, L. (1991) Trophic levels and trophic dynamics: a consensus emerging? Trends Ecol. Evol. 6, 58-60 